\title{
Faktor-faktor yang berhubungan dengan keterlambatan perkembangan bayi usia 9 bulan
}

\author{
${ }^{1}$ Stephanie K. I. Tilaar \\ ${ }^{2}$ Hesti Lestari \\ ${ }^{2}$ Ari L. Runtunuwu
}

\author{
${ }^{1}$ Kandidat Skripsi Fakultas Kedokteran Universitas Sam Ratulangi Manado \\ ${ }^{2}$ Bagian Ilmu Kesehatan Anak Kedokteran Universitas Sam Ratulangi Manado \\ Email: keziatilaar@yahoo.com
}

\begin{abstract}
Children are the next generation of a nation, therefore, to achieve a better future, the children must have qualified growth and development. During the infant and toddler stages ( $0-3$ years old), children growth depends on the environment. This stdy was aimed to obtain the risk factors of developmental delay in infant of 9 months old. This was an analytical survey study with a cross sectional design. This study was conducted at Bahu Health Centre in Manado from October until December 2015. Samples were all infants of 9 months old obtained by using consecutive sampling technique. Data were analyzed by using bivariate analysis with the chi square test. The results showed that health care, breastfeeding, and the number of siblings had no relationship with the developmental delay in infant 9 month old $(p>0.05)$. The family income showed 29.333 times of risk that an infant would have developmental delay $(\mathrm{p}=0.006)$ meanwhile low education showed 14.000 times of risk for that $(\mathrm{p}=0.016)$. Conclusion: There is a relationship between parent education and family income with the developmental delay in infants of 9 month olds.
\end{abstract}

Keywords: developmental delay, infant 9 month old.

\begin{abstract}
Abstrak: Anak merupakan generasi penerus suatu bangsa dan agar tercapai masa depan bangsa yang baik. Untuk mencapai hal tersebut harus dipastikan bahwa tumbuh dan kembangnya juga baik. Pada masa bayi dan masa anak dini (usia 0-3 tahun) terjadi perkembangan bayi sesuai dengan lingkungan yang memengaruhinya. Penelitian ini bertujuan untuk mengetahui faktor risiko terjadinya keterlambatan perkembangan bayi usia 9 bulan. Jenis penelitian ialah survei analitik dengan desain potong lintang. Penelitian dilakukan di Puskesmas Bahu Kota Manado pada bulan Oktober sampai Desember 2015 dengan populasi semua bayi 9 bulan yang datang di puskesmas. Penentuan sampel menggunakan teknik konsekutif sampling. Analisis data bivariat menggunakan uji statistik chi-square. Hasil penelitian menunjukkan bahwa perawatan kesehatan, pemberian ASI, dan jumlah saudara tidak memiliki hubungan bermakna terhadap perkembangan bayi usia 9 bulan ( $p>0,05$ ). Pendapatan keluarga berisiko 29,333 kali lebih banyak untuk mengalami keterlambatan perkembangan $(\mathrm{p}=0,006)$ dan pendidikan rendah berisiko 14,000 kali lebih banyak untuk mengalami hal tersebut $(\mathrm{p}=0,016)$. Simpulan: Terdapat hubungan antara pendidikan dan pendapatan orang tua dengan keterlambatan perkembangan pada bayi 9 bulan.
\end{abstract}

Kata kunci: perkembangan, bayi 9 bulan

Anak merupakan generasi penerus suatu bangsa, dengan demikian dibutuhkan anak dengan kualitas yang baik agar tercapai masa depan bangsa yang baik. Untuk mendapatkan kualitas anak yang baik harus dipastikan bahwa tumbuh dan kembang 
anak juga baik. ${ }^{1,2}$

Pada umumnya anak memiliki pola perkembangan normal yang merupakan hasil interaksi banyak faktor yang memengaruhi perkembangan anak. Faktorfaktor tersebut adalah faktor genetik dan faktor lingkungan diantaranya biofisikopsikososial, yang bisa menghambat dan mengoptimalkan perkembangan anak. ${ }^{2,3}$ Perkembangan anak juga mengacu pada terpenuhinya kebutuhan anak akan ASUH, ASIH, dan $\mathrm{ASAH}^{4}$ Penelitian terdahulu menunjukkan hasil skrining perkembangan yang berbeda-beda, dengan rentang nilai sebesar 13-28,5\% dengan keterlambatan tidak teridentifikasi tanpa skrining, sedangkan $70-80 \%$ anak dengan keterlambatan perkembangan teridentifikasi dengan skrining perkembangan yang baik. ${ }^{5}$

Pada masa bayi dan masa anak dini (usia 0-3 tahun) terjadi perkembangan bayi sesuai dengan lingkungan yang memengaruhinya dan juga terjadi perkembangan yang cepat dalam aspek sifat, sikap, minat, dan cara penyesuaian dengan lingkungan. ${ }^{6}$ Skrining perkembangan untuk deteksi dini pada setiap anak penting dilakukan, terutama pada anak sampai usia 1 tahun agar bila ditemukan kecurigaan penyimpangan perkembangan dapat segera dilakukan intervensi dini sebelum terjadi kelainan. Dari beberapa sumber kepustakaan didapatkan bahwa intervensi pada anak dengan kecurigaan penyimpangan perkembangan sebaiknya dilakukan sebelum usia 3 tahun. Usia 9 bulan merupakan salah satu usia yang termasuk dalam jadwal skrining perkembangan. ${ }^{7}$

Kuesioner Pra Skrining Perkembangan (KPSP) merupakan salah satu alat skrining untuk mendeteksi dini adanya kelainan perkembangan anak sejak usia 3 bulan sehingga dengan cepat dapat dilakukan intervensi dini. ${ }^{8}$

\section{METODE PENELITIAN}

Jenis penelitian ini ialah analitik dengan desain potong lintang. Penelitian ini dilaksanakan di Puskesmas Bahu Kota Manado, Sulawesi pada bulan Oktober Desember 2015. Populasi penelitian ialah semua bayi 9 bulan yang datang di
Puskesmas Bahu dan semua orang tua yang bersedia mengikuti penelitian. Sampel penelitian diambil menggunakan metode konsekutif sampling. Analisis deskriptif yang ditampilkan dalam bentuk tabel distribusi. Analisis hubungan antara variabel bebas (pemberian ASI, perawatan kesehatan, pendidikan orang tua, pendapatan orang tua, jumlah saudara) dengan variabel terikat (perkembangan anak) menggunakan uji chi square. Data penelitian ini diolah menggunakan komputer dengan program SPSS 21.0.

\section{HASIL PENELITIAN}

Penelitian ini dilaksanakan di Puskemas Bahu pada setiap jadwal imunisasi. Sampel ialah bayi berusia 9 bulan yang melakukan imunisasi campak di puskesmas dan orang tua yang bersedia mengikuti penelitian, dan tercatat sebanyak 30 sampel. Berdasarkan Tabel 1, dari 30 sampel terdapat 19 bayi jenis kelamin perempuan $(63,4 \%)$ dan 11 bayi jenis kelamin laki-laki (36,6\%); 23 bayi (76,7\%) dengan KPSP yang sesuai dan 7 bayi $(23,3 \%)$ dengan KPSP yang tidak sesuai; 22 anak pemberian asi ekslusif $(73,3 \%)$ dan 8 anak tidak ekslusif (26,7\%); 25 bayi $(83,3 \%)$ dengan pendapatan orang tua tinggi dan 8 bayi $(16,7 \%)$ dengan pendapatan orang tua; 24 bayi $(80 \%)$ dengan pendidikan orang tua tinggi dan 6 bayi $(20 \%)$ dengan pendidikan orang tua rendah; 27 bayi (90\%) dengan jumlah saudara yang sedikit dan 3 bayi (10\%) dengan jumlah saudara yang banyak; 22 bayi $(73,3 \%)$ mendapatkan perawatan kesehatan yang baik dan 8 anak $(26,7 \%)$ dengan perawatan kesehatan buruk.

Pada Tabel 2 dapat dilihat bahwa dari 22 anak yang mendapatkan ASI eksklusif, 17 anak mengalami perkembangan normal dan 5 anak mengalami keterlambatan. Dari 8 anak yang tidak diberikan ASI ekslusif 6 anak mengalami perkembangan normal dan 2 anak mengalami keterlambatan. Hasil uji chi-square menyatakan tidak ada hubungan bermakna antara pemberian asi dan perkembangan pada bayi 9 bulan ( $\mathrm{p}=$ 0,623). 
Tabel 1. Karateristik sampel

\begin{tabular}{lcc}
\hline Karateristik & N & \% \\
\hline Jenis kelamin & & \\
$\quad$ Laki-laki & 11 & 36,6 \\
Perempuan & 19 & 63,4 \\
Pemberian ASI & & \\
$\quad$ Ekslusif & 22 & 73,3 \\
$\quad$ Tidak Ekslusif & 8 & 26,7 \\
Pendapatan orang tua & & \\
$\quad$ Tinggi & 25 & 83,3 \\
$\quad$ Rendah & 5 & 16,7 \\
Pendidikan & & \\
$\quad$ Tinggi & 24 & 80 \\
$\quad$ Rendah & 6 & 20 \\
Jumlah saudara & & \\
$\quad$ Sedikit & 27 & 90 \\
$\quad$ Banyak & 3 & 10 \\
Perawatan kesehatan & & \\
$\quad$ Baik & 22 & 73,3 \\
Buruk & 8 & 26,7 \\
\hline
\end{tabular}

Tabel 2. Hubungan pemberian ASI dengan keterlambatan perkembangan

\begin{tabular}{|c|c|c|c|}
\hline \multirow{2}{*}{$\begin{array}{c}\text { Pemberian } \\
\text { ASI }\end{array}$} & \multicolumn{2}{|c|}{ Perkembangan } & \multirow{2}{*}{$\begin{array}{c}\text { Jumlah } \\
(\%)\end{array}$} \\
\hline & $\begin{array}{c}\text { Normal } \\
\text { n }(\%)\end{array}$ & $\begin{array}{c}\text { Terlambat } \\
\text { n }(\%)\end{array}$ & \\
\hline $\begin{array}{l}\text { Eksklusif } \\
\text { Tidak }\end{array}$ & $17(20,0)$ & $5(6,7)$ & $22(73,3)$ \\
\hline ek & $6(56$ & $2(10$ & $8(26$, \\
\hline Jumlah & $23(76,7)$ & $7(23,3)$ & $30(100,0)$ \\
\hline
\end{tabular}

Pada Tabel 3 dapat dilihat bahwa dari 22 anak yang mendapatkan perawatan kesehatan baik, 18 anak mengalami perkembangan normal dan 4 anak mengalami keterlambatan. Dari 8 anak yang mendapatkan perawatan kesehatan buruk, 5 anak mengalami perkembangan normal dan 3 anak mengalami keterlambatan. Hasil uji chi-square menyatakan tidak ada hubungan bermakna antara perawatan kesehatan dan perkembangan bayi 9 bulan $(\mathrm{p}=0,261)$.

Tabel 3. Hubungan perawatan kesehatan dan perkembangan bayi 9 bulan

\begin{tabular}{lccc}
\hline \multirow{2}{*}{$\begin{array}{c}\text { Perawatan } \\
\text { kesehatan }\end{array}$} & $\begin{array}{c}c \\
\text { Normal } \\
\text { n (\%) }\end{array}$ & $\begin{array}{c}\text { Perlambat } \\
\text { n (\%) }\end{array}$ & Jumlah (\%) \\
\hline Baik & $18(60,0)$ & $4(13,3)$ & $22(73,3)$ \\
Buruk & $5(16,7)$ & $3(10,0)$ & $8(26,7)$ \\
Jumlah & $23(76,7)$ & $7(23,3)$ & $30(100,0)$ \\
\hline
\end{tabular}

Pada Tabel 4 dapat dilihat bahwa dari 25 anak yang pendapatan keluarganya tinggi, 22 anak mengalami perkembangan normal dan 3 anak mengalami keterlambatan. Dari 5 anak pendapatan keluarga rendah 1 anak mengalami perkembangan normal dan 4 anak mengalami keterlambatan. Hasil uji chisquare menyatakan ada hubungan bermakna antara pendapatan keluarga dan keterlambatan perkembangan bayi 9 bulan $(\mathrm{p}=0,006)$ dengan $\mathrm{OR}=29,333$ berarti faktor pendapatan keluarga rendah berisiko 29,333 kali lebih banyak untuk mengalami keterlambatan perkembangan.

Pada Tabel 5 dapat dilihat bahwa dari 27 anak yang jumlah saudaranya sedikit, 22 anak mengalami perkembangan normal dan 5 anak mengalami keterlambatan. Dari 3 anak yang jumlah saudaranya banyak, 1 anak mengalami perkembangan normal dan 2 anak mengalami keterlambatan. Hasil uji chisquare menyatakan tidak ada hubungan bermakna antara jumlah saudara dan perkembangan orang tuanya tinggi, 21 anak mengalami perkembangan normal dan 3 anak mengalami keterlambatan. Dari 8 anak yang orang tuanya berpendidikan rendah 2 anak mengalami perkembangan normal dan 4 anak mengalami keterlambatan. Hasil uji chisquare menyatakan ada hubungan bermakna antara pendidikan orang tua dan keterlambatan bayi usia 9 bulan $(\mathrm{p}=0,016)$ dengan $\mathrm{OR}=14,000$ Berarti faktor pendidikan rendah berisiko 14,000 kali lebih banyak untuk mengalami keterlambatan perkembangan. 
Tilaar, Lestari, Runtunuwu: Faktor-faktor yang...

Tabel 4. Hubungan pendapatan keluarga dan perkembangan bayi 9 bulan

\begin{tabular}{lccc}
\hline \multirow{3}{*}{ Pendapatan keluarga } & \multicolumn{2}{c}{ Perkembangan } & \\
& Normal & Terlambat & Jumlah (\%) \\
& $\mathbf{n}(\boldsymbol{\%})$ & $\mathbf{n}(\boldsymbol{\%})$ & \\
\hline Tinggi & $22(73,3)$ & $3(10,0)$ & $25(83,3)$ \\
Rendah & $1(3,3)$ & $4(13,3)$ & $5(16,7)$ \\
Jumlah & $23(76,7)$ & $7(23,3)$ & $30(100,0)$ \\
\hline
\end{tabular}

Tabel 5. Hubungan jumlah saudara dan perkembangan bayi usia 9 bulan

\begin{tabular}{lccc}
\hline \multirow{4}{*}{ Jumlah saudara } & \multicolumn{2}{c}{ Perkembangan } & \\
& Normal & Terlambat & Jumlah (\%) \\
& $\mathbf{n}(\boldsymbol{\%})$ & $\mathbf{n}(\boldsymbol{\%})$ & \\
\hline Sedikit & $22(73,3)$ & $5(16,7)$ & $27(90,0)$ \\
Banyak & $1(3,3)$ & $2(6,7)$ & $3(10,0)$ \\
Jumlah & $23(76,7)$ & $7(23,3)$ & $30(100,0)$ \\
\hline
\end{tabular}

Tabel 6. Hubungan pendidikan orang tua dan perkembangan bayi 9 bulan

\begin{tabular}{|c|c|c|c|}
\hline \multirow[b]{2}{*}{$\begin{array}{c}\text { Pendidikan } \\
\text { orang tua }\end{array}$} & \multicolumn{2}{|c|}{ Perkembangan } & \multirow[b]{2}{*}{ Jumlah (\%) } \\
\hline & $\begin{array}{c}\text { Normal } \\
\text { n }(\%)\end{array}$ & $\begin{array}{c}\text { Terlambat } \\
\text { n }(\%)\end{array}$ & \\
\hline Tinggi & $21(70,0)$ & $3(10,0)$ & $24(80,0)$ \\
\hline Rendah & $2(6,7)$ & $4(13,3)$ & $6(20,0)$ \\
\hline Jumlah & $23(76,7)$ & $7(23,3)$ & $30(100,0)$ \\
\hline
\end{tabular}

\section{BAHASAN}

Penelitian ini dilaksanakan di Puskesmas Bahu yang berada di Kota Manado. Sampel ialah bayi dengan usia 9 bulan dan orang tua yang bersedia mengikuti penelitian, dan tercatat sebanyak 30 sampel. Dari 30 sampel tersebut, 11 diantaranya laki-laki $(36,6 \%)$ dan 19 perempuan $(63,4 \%)$. Dari 30 sampel tersebut diperoleh 23 bayi $(76,6 \%)$ mengalami perkembangan sesuai usia dan 7 bayi $(23,4 \%)$ mengalami keterlambatan perkembangan.

Hasil uji chi-square mendapatkan bahwa pemberian ASI tidak memiliki hubungan bermakna terhadap keterlambatan perkembangan anak $(\mathrm{p}=0,623)$. Hasil penelitian ini berbeda dengan penelitian yang dilakukan oleh Lidya dan Rodiah ${ }^{9}$ di Puskesmas Karanganyar tahun 2010 bahwa terdapat hubungan bermakna antara pemberian ASI dengan perkembangan bayi. Penelitian Kharmina ${ }^{10}$ di lingkungan Puskesmas Cigondewah Bandung menyimpulkan bahwa aspek kognitif pada bayi yang mendapat ASI eksklusif memberikan hasil lebih baik disbanding dengan bayi yang tidak mendapat ASI eksklusif. Berdasarkan uji chi square didapatkan bahwa perawatan kesehatan bayi tidak memiliki hubungan bermakna terhadap keterlambatan perkembangan anak dimana ( $\mathrm{p}=0,261)$. Hasil penelitian ini berbeda dengan penelitian Susan di wilayah kerja Puskesmas Sukakarya Kabupaten Garut yang menunjukkan bahwa perawatan kesehatan merupakan faktor penting dalam mengoptimalkan perkembangan anak. ${ }^{11}$ Hubungan perawatan kesehatan tidak bermakna dengan keterlambatan perkembangan mungkin disebabkan oleh semakin tingginya tingkat kesadaran perawatan kesehatan oleh orang tua ketika anak sakit, imunisasi yang rutin, termasuk pemantauan pertumbuhan, dengan menimbang anak secara rutin setiap bulan.

Berdasarkan hasil uji chi-square didapatkan bahwa pendapatan keluarga 
memiliki hubungan bermakna terhadap keterlambatan perkembangan bayi ( $\mathrm{p}$ $=0,006$ dan $0 \mathrm{R}=29,33$ ). Hasil penelitian ini berbeda dengan penelitian yang dilakukan oleh Sarah ${ }^{12}$ yang menunjukkan bahwa keadaan ekonomi keluarga yang kurang mampu merupakan faktor yang kurang mendukung bagi pertumbuhan dan perkembangan anak. Penelitian ini juga selaras dengan penelitian Djola ${ }^{13}$ di Desa Bongkudai Kecamatan Modayag Barat tahun 2011 bahwa tidak terdapat hubungan. Hal ini disebabkan karena tingkat pendapatan keluarga sangat berpengaruh terhadap konsumsi pangan keluarga.

Berdasarkan hasil uji chi-square didapatkan tidak ada hubungan bermakna antara jumlah saudara dan perkembangan anak $(p=0,128)$. Hasil penelitian ini tidak sejalan dengan teori yang menyatakan jumlah anak yang banyak pada keluarga dapat menyebabkan kurangnya perhatian dan kasih sayang yang diterima anak. Suasana emosional dalam rumah, sangat merangsang perkembangan otak anak yang sedang tumbuh dan mengembangkan kemampuan mentalnya. ${ }^{14}$ Jadi, hasil penelitian tidak bermakna mungkin disebabkan oleh pemerataan pemenuhan kebutuhan kasih sayang dan perhatian sehingga setiap aspek perkembangan dapat berjalan dengan baik.

Berdasarkan hasil uji chi-square didapatkan bahwa pendidikan orang tua memiliki hubungan bermakna terhadap keterlambatan perkembangan anak $(\mathrm{p}=$ $0,016)$. Hasil penelitian ini sejalan dengan teori bahwa tingkat pendidikan orang tua yang berbeda-beda akan memengaruhi kegiatan orang tua dalam melaksanakan pengasuhan anak-anaknya. Masing-masing orang tua tentu saja memiliki pola asuh tersendiri dalam mengarahkan perilaku anak. Orang tua dengan pendidikan yang baik dapat menerima informasi dari luar tentang cara pola pengasuhan anak, menjaga kesehatan anak, serta cara mendidiknya. ${ }^{15}$

\section{SIMPULAN}

Dari hasil penelitian ini dapat disimpulkan bahwa pendidikan dan pendapatan orang tua memengaruhi keterlambatan perkembangan pada bayi berusia 9 bulan.

\section{SARAN}

1. Walaupun pendapatan keluarga rendah, hendaknya orang tua harus lebih memperhatikan perkembangan bayi, kebutuhan bayi harus lebih diutamakan.

2. Bagi setiap orang tua harus mencaritahu tentang perkembangan bayi normal dan tidak.

3. Perlu dilakukan penelitian lebih lanjut lagi terhadap faktor-faktor yang berhubungan dengan keterlambatan pada bayi 9 bulan.Hasil dari penelitian ini telah diketahui orang tua anak,baik yang mengalami perkembangan normal maupun mengalami keterlambatan perkembangan.

\section{DAFTAR PUSTAKA}

1. Soetjiningsih. Tumbuh kembang anak. In: Ranuh IGN, penyunting. Tumbuh Kembang Anak. Jakarta: EGC, 1995.

2. Moersintowati. Deteksi dini tumbuh kembang. Simposium piñatalaksanaan mutakhir bidang ilmu kesehatan anak untuk mencapai tumbuh kembang optimal. Bandung: IDAI Jawa Barat, 2000.

3. Soetjiningsih. Faktor-Faktor yang mempengaruhi tumbuh kembang anak. In: Ranuh IGNG, penyunting. Tumbuh Kembang Anak (2nd ed). Jakarta: EGC, 2012; p. 61-71.

4. Sularyo TS. Pertumbuhan linier (Stature) anak dan upaya pemantauannya. Buku Saku Ilmu Penyakit Anak untuk Pemula. Jakarta, 2002.

5. Perkembangan Anak. Jakarta: Departemen Kesehatan Republik Indonesia, 1990.

6. Depkes. Skrining Perkembangan Bayi di Indonesia. Jakarta: Direktorat Bina Kesehatan Anak Kementerian Kesehatan RI, 2003.

7. Fida, Maya. Pola pertumbuhan dan perkembangan. Pengantar Ilmu Kesehatan Anak. Jogjakarta: DMedika, 2012; p. 27.

8. Darmosubroto S. Instrumen pemantauan 
Tilaar, Lestari, Runtunuwu: Faktor-faktor yang...

tumbuh kembang anak. In: Pusponegoro HD, Taslim, penyunting. Deteksi dan intervensi dini penyimpangan tumbuh kembang anak dalam upaya optimalisasi kualitas sumber daya manusia. Pendidikan Kedokteran Berkelanjutan Ilmu Kesehatan Anak. Jakarta: FKUI, 1996; p. 125-31.

9. Lidya NM, Rodiah. Hubungan pemberian ASI dengan tumbuh kembang pada anak usia 3 sampai 6 bulan di Puskesmas Karanganyar. [serial online] 2010. [cited 12 Juni 2013]. Available from: https://es.scribd.com.

10. Novita L, Dida A, Gurnida, Herry G. Perbandingan fungsi kognitif bayi usia 6 bulan yang mendapat dan yang tidak mendapat ASI eksklusif. Sari Pediatri. 2007;9(6):429-34

11. Kharmina N. Hubungan antara tingkat pendidikan orang tua dengan pola asuh anak usia dini [Skripsi].
Semarang: Fakultas Ilmu Pendidikan Universitas Negeri Semarang; 2011.

12. Sarah M. Hubungan tingkat sosial ekonomi dan pola asuh dengan status gizi anak balita di wilayah kerja puskesmas pantai cermin kecamatan tanjung Pura Kabupaten Langkat [Skripsi]. Medan: Fakutas Kesehatan Masyarakat Universitas Sumatra Utara; 2008.

13. Djola R. Hubungan antara tingkat pendapatan dan pola asuh dengan status gizi balita di desa Bongkudai Kecamatan Modayag Barat. Manado: Fakultas Kesehatan Masyarakat Universitas Sam Ratulangi; 2011:5560.

14. Suryabrata S. Psikologi Pendidikan. Jakarta: Rajawali, 2000.

15. Fridani, Lara, Lestari APE. Inspiring education PAUD. Jakarta: PT. Alex Media Komputindo, 2009. 